\title{
Estudo do processo de sacarificação da crueira visando a produção de bioetanol
}

Study of the crueira's hydrolysis to produce bioethanol

\author{
S. S. Costa ${ }^{1}$; A. M. Santos ${ }^{1}$; R. R. de Souza ${ }^{1}$; C. F. Silva ${ }^{1 *}$ \\ ${ }^{1}$ Departamento de Engenharia Química/Centro de Ciências Exatas e Tecnologia/ Universidade Federal de \\ Sergipe, 49100-000, São Cristóvão-Sergipe, Brasil.
}

*ferrazcristina@ufs.br

(Recebido em 31 de janeiro de 2016; aceito em 30 de março de 2016)

\begin{abstract}
Matérias-primas como o amido vêm sendo estudadas como grande potencial para a produção de etanol, principalmente por serem encontradas em abundância na natureza. A mandioca destaca-se por ser uma planta tuberosa típica das regiões tropicais e o Brasil é um dos grandes produtores globais. Para fins industriais, a mandioca vem sendo utilizada principalmente para a produção da farinha de mandioca, gerando diversos resíduos. Dentre eles está a crueira, a qual compreende um resíduo sólido rico em amido e gerado em abundância após a etapa de moagem e esfarelamento da mandioca. Entretanto, para os processos fermentativos é necessário que a crueira seja primeiramente hidrolisada para a conversão do amido em açúcares fermentescíveis. Diante do potencial desse substrato para bioconversão, o presente trabalho estudou o processo de hidrólise enzimática da crueira através de planejamento experimental fatorial completo $2^{2}$ para analisar a influência da quantidade de extrato enzimático bruto e a concentração de crueira no processo de sacarificação. Os resultados do planejamento experimental demostraram que a variável concentração de crueira foi estatisticamente significativa. A melhor faixa de sacarificação obtida foi de 100 a $108 \mathrm{~g} / \mathrm{L}$ de crueira e $70 \mathrm{~mL}$ de extrato enzimático atingindo $10^{\circ}$ Brix. Os ensaios cinéticos demonstraram que 20h é o tempo necessário para atingir o máximo da sacarificação.
\end{abstract}

Palavras-chave: crueira, sacarificação, etanol

The raw materials such as starch have been studied as great potential for the production of ethanol, mainly because they are found abundantly in nature. Cassava stands out for being a typical tuberous plant of the tropics and Brazil is one of the major global producers. For industrial purposes, cassava has been used mainly for the production of cassava flour, generating several wastes. Among them is the crueira, which comprises a solid residue rich in starch and generated in abundance after the step of milling and flaking of cassava. However, for fermentation processes it is necessary that crueira is first hydrolyzed to convert the starch into fermentable sugars. Due to the potential of this substrate for bioconversion, this paper studied the enzymatic hydrolysis process of crueira through a full factorial experimental design $2^{2}$ to analyze the influence of the amount of crude enzyme extract (a-amylase) and the concentration of crueira in the saccharification process. The results demonstrated that the experimental design variable concentration crueira was statistically significant. The best range obtained by saccharification was 100 to $108 \mathrm{~g} / \mathrm{L}$ crueira and $70 \mathrm{~mL}$ enzyme extract $10^{\circ}$ Brix reached after $24 \mathrm{~h}$ of hydrolysis. Kinetic studies demonstrated that $20 \mathrm{~h}$ is the time required to reach maximum saccharification.

Keywords: crueira, saccharification, ethanol

\section{INTRODUÇÃO}

Por ser um país que tem a agricultura como base, o Brasil gera uma quantidade considerável de resíduos agroindustriais. A utilização desses resíduos como coprodutos para a produção de bioetanol demonstra uma fonte alternativa de matéria-prima, bem como uma possibilidade de redução dos custos de produção. Além disso, o uso de resíduos para a produção de biocombustíveis renováveis contribui para o desenvolvimento da agricultura familiar e também demonstra uma destinação alternativa e menos agressiva ao meio ambiente [1].

Dentre as principais culturas desenvolvidas no Brasil está a mandioca, a qual compreende uma raiz tuberosa rica em amido e encontrada em toda extensão do território nacional [2]. A mandioca pode receber diferentes tipos de beneficiamento, sendo um deles o processo de produção da farinha. Este gera diversos resíduos em quantidades significativas, sendo necessário o reaproveitamento desses materiais. Dentre eles, destaca-se a crueira, resíduo sólido rico em amido 
obtido na etapa de peneiramento da massa de mandioca ralada. A crueira é composta por pedaços de casas, entrecascas e raízes da mandioca [3].

$\mathrm{O}$ amido presente na crueira pode ser usado como matéria-prima para a produção de bioetanol. No entanto, a bioconversão desse resíduo amiláceo é necessária para a obtenção de açúcares fermentescíveis, tendo em vista que a levedura Saccharomyces cerevisiae não é capaz de converter o amido a etanol diretamente [4]. Nesse processo denominado de hidrólise ou sacarificação enzimática se faz necessário o uso de enzimas amilolíticas, que podem ser de origem vegetal ou microbiana [5].

Nesse contexto, o presente trabalho teve como objetivo estudar o processo de hidrólise do resíduo amiláceo (crueira), utilizando um extrato enzimático produzido por Bacillus sp. e avaliar o potencial da crueira para a produção de bioetanol.

\section{MATERIAL E MÉTODOS}

\subsection{Produção do extrato bruto enzimático}

\subsubsection{Microrganismo}

A cepa ANRAS02 utilizada nesse estudo é parte integrante da coleção de microrganismos do Grupo de Pesquisa em Biotecnologia Industrial do Departamento de Engenharia Química da Universidade Federal de Sergipe. ANRAS02 compreende uma bactéria Gram positiva presente na forma de bacilo e identificada como Bacillus sp. A cepa ANRAS02 foi isolada de manguezal na Reserva Biológica de Santa Isabel (REBIO), ao longo do canal do Parapuca, na Região de Ponta dos Mangues no município de Pacatuba, Sergipe.

\subsubsection{Inóculo}

A cepa ANRAS02 foi preparada, em meio caldo nutriente, na forma de um pré-inóculo e, posteriormente, de um inóculo até a obtenção da quantidade de células viáveis necessárias para iniciar o processo fermentativo. Uma alíquota com $5 \mathrm{~mL}$ do inóculo padronizado ( $10^{7}$ células $/ \mathrm{mL}$ ) foi adicionada ao erlenmeyer contendo meio de produção da enzima.

\subsubsection{Preparo do meio de produção da enzima}

Foram adicionados $1 \mathrm{~g}$ de amido solúvel em um erlenmeyer de $150 \mathrm{ml}$, uma solução tampão para a correção do pH 6,0 e uma solução nutriente composta por $\mathrm{MgSO}_{4}, \mathrm{KH}_{2} \mathrm{PO}_{4}, \mathrm{CaCl}_{2}, \mathrm{FeSO}_{4}$ e extrato de levedura, para atender as necessidades nutricionais do microrganismo. O erlenmeyer contendo o meio de produção foi esterilizado em autoclave a pressão de 1 atm e temperatura de $121^{\circ} \mathrm{C}$ durante 15 minutos. Após, o inóculo contendo o microrganismo foi adicionado ao erlenmeyer.

\subsubsection{Fermentação submersa e obtenção do extrato enzimático}

Para a obtenção da enzima, o erlenmeyer contendo o meio de produção inoculado com o microrganismo Bacillus sp. ANRAS02 foi incubado durante $24 \mathrm{~h}$ em agitador rotativo tipo shaker. A obtenção do extrato enzimático bruto ocorreu após a centrifugação do fermentado a $4200 \mathrm{rpm}$ por $15 \mathrm{~min}$. O cálculo da atividade enzimática seguiu o método descrito por Xiao (2006) com modificações, conforme Equação 01 [6].

$$
\mathrm{U} / \mathrm{mL}=\frac{(\text { Acontrole }+ \text { Ainicial })-\text { Aamostra })}{(0,153 \times \mathrm{t} \times 0,01 \times 0,33)}
$$

Sendo:

A controle $=$ absorbância da solução controle de amido;

A inicial = absorbância do controle da amostra antes da reação;

A amostra = absorbância da amostra de extrato enzimático reagido; 
$\mathrm{t}=$ tempo de reação da amostra com a solução de iodo.

2.2 Processo de sacarificação da crueira

\subsubsection{Pré-tratamento da crueira}

A crueira foi inicialmente levada à estufa à temperatura de aproximadamente $60^{\circ} \mathrm{C}$ por $18 \mathrm{~h}$ e em seguida resfriada em dessecador até temperatura ambiente. Após esse período, o resíduo foi homogeneizado até atingir o aspecto de farinha e peneirado para a padronização do tamanho das partículas.

\subsubsection{Planejamento Experimental}

O estudo do processo de sacarificação foi realizado através um Planejamento Experimental Fatorial Completo $2^{2}$ com pontos centrais e axiais, incluindo as variáveis quantidade de extrato enzimático bruto $\left(\mathrm{x}_{1}\right)$ e concentração de crueira $\left(\mathrm{x}_{2}\right)$. Os valores reais estudados para cada uma das variáveis são apresentados na Tabela 1. Os ensaios do Planejamento foram realizados em erlenmeyers de $250 \mathrm{~mL}$ e as quantidades de cada variável seguiram a descrição apresentada na matriz contida na Tabela 2 .

Todos os ensaios do Planejamento foram submetidos a diferentes etapas de hidrólise, onde em uma primeira etapa, foram adicionados $10 \mathrm{~mL}$ do extrato enzimático e a mistura foi incubada a $60^{\circ} \mathrm{C}$ durante $1 \mathrm{~h}$ sob agitação de $100 \mathrm{rpm}$. Após essa fase, os hidrolisados foram autoclavados a pressão de $1 \mathrm{~atm}$ e temperatura de $121^{\circ} \mathrm{C}$ para que ocorresse a gelatinização do amido. $\mathrm{O}$ sistema sofreu arrefecimento até atingir $60^{\circ} \mathrm{C}$ (temperatura ótima de atuação da enzima), sendo, posteriormente, adicionado o volume correspondente de extrato enzimático bruto, conforme Tabela 2. O volume final de todos os ensaios foi de $150 \mathrm{~mL}$, sendo atingido com a adição de água destilada. O processo de hidrólise em todos os ensaios foi desenvolvido com agitação de $150 \mathrm{rpm}$, $\mathrm{pH} 5,0$ e $60^{\circ} \mathrm{C}$ durante $24 \mathrm{~h}$ [7]. O acompanhamento do processo de hidrólise do amido foi realizado através da retirada de alíquotas para a realização das análises de ${ }^{\circ}$ Brix. Os valores obtidos para o resultado foram analisados através do Software Statistic 7.0.

Tabela 1. Valores reais das variáveis utilizadas no Planejamento Experimental Fatorial Completo $2^{2}$ para sacarificação da crueira.

\begin{tabular}{|c|c|c|c|c|c|}
\hline Variável & $-1,41$ & -1 & 0 & 1 & 1,41 \\
\hline $\begin{array}{l}\text { Volume do extrato } \\
\text { bruto de enzima }(\mathrm{mL}) \\
\left(\mathrm{x}_{1}\right)\end{array}$ & 41,8 & 50 & 70 & 90 & 98,2 \\
\hline $\begin{array}{c}\text { Concentração de } \\
\text { crueira }(\mathrm{g} / \mathrm{L}) \\
\left(\mathrm{x}_{2}\right)\end{array}$ & 51,8 & 60 & 80 & 100 & 108,2 \\
\hline
\end{tabular}


Tabela 2. Matriz do Planejamento Experimental Fatorial Completo $2^{2}$ para sacarificação da crueira.

\begin{tabular}{ccc}
\hline Ensaios & $\begin{array}{c}\text { Volume do extrato } \\
\text { enzimático bruto }(\mathrm{mL}) \\
\left(\mathrm{x}_{1}\right)\end{array}$ & $\begin{array}{c}\text { Concentração de } \\
\text { crueira }(\mathrm{g} / \mathrm{L}) \\
\left(\mathrm{x}_{2}\right)\end{array}$ \\
\hline 1 & -1 & -1 \\
2 & +1 & -1 \\
3 & -1 & +1 \\
4 & +1 & +1 \\
5 & $-1,41$ & 0 \\
6 & $+1,41$ & 0 \\
7 & 0 & $-1,41$ \\
8 & 0 & $+1,41$ \\
9 & 0 & 0 \\
10 & 0 & 0 \\
11 & 0 & 0 \\
\hline
\end{tabular}

\subsubsection{Determinação do ${ }^{\circ}$ Brix}

A sacarificação foi analisada com base nos açúcares totais presentes no meio ao fim de cada uma das etapas do processo. As alíquotas retiradas do mosto foram utilizadas para a análise do ${ }^{\circ}$ Brix usando um refratômetro [8].

\subsection{Determinação da Cinética de sacarificação da crueira}

Para o desenvolvimento da cinética de sacarificação do amido da crueira, foi determinado o ensaio do Planejamento Experimental com melhor resultado dos sólidos solúveis ( ${ }^{\circ} \mathrm{Brix}$ ) e reproduzidos em triplicata. Os ensaios foram analisados a cada 4 horas durante 44 horas de sacarificação e retiradas alíquotas do hidrolisado para medir o valor do ${ }^{\circ}$ Brix da mistura com refratômetro.

\section{RESULTADOS E DISCUSSÃO}

A atividade enzimática obtida no extrato bruto produzido com o microrganismos Bacillus sp. ANRAS02 foi 30,72 U/mL. O resultado obtido concorda com a atividade enzimática apresentada em estudos realizados por Carvalho (2007), a qual foi de $30,87 \mathrm{U} / \mathrm{mL}$, utilizando amido solúvel como substrato e $72 \mathrm{~h}$ de fermentação [9]. Já os valores descritos por Rabalho (2002), demonstram uma faixa de 2,28 a 4,01 $\mathrm{U} / \mathrm{mL}$ para a atividade de enzimas amilolíticas produzidas por fermentação submersa [7].

O processo de pré-tratamento da crueira, realizado antes das etapas de hidrólise, contribuiu significativamente para o aumento da superfície de contato, facilitando a gelatinização ou entumecimento dos grânulos de amido. Com isso, promovendo uma maior disponibilidade das cadeias amilose e amilopectina ao ataque enzimático, tornando mais eficaz a atuação das enzimas contidas no extrato. 
Na Tabela 3 são apresentados os resultados obtidos nas análises de ${ }^{\circ}$ Brix para os ensaios de sacarificação da farinha de crueira, desenvolvidos no planejamento Experimental Fatorial Completo $2^{2}$.

Tabela 3. Resultado do Planejamento Experimental Planejamento Experimental Fatorial Completo $2^{2}$.

\begin{tabular}{ccc}
\hline Ensaio & ${ }^{\circ}$ Brix Inicial & ${ }^{\circ}$ Brix Final \\
\hline 1 & 1 & 7 \\
2 & 2 & 6 \\
3 & 1 & 10 \\
4 & 2 & 9 \\
5 & 1 & 7 \\
6 & 2 & 8 \\
7 & 1 & 6 \\
8 & 2 & 10 \\
9 & 1 & 7 \\
10 & 10 & 8 \\
11 & 1 & 8 \\
\hline
\end{tabular}

Os resultados apresentados na Tabela 3 demonstram que houve aumento dos sólidos solúveis ( ${ }^{\circ}$ Brix) no processo de sacarificação. Os valores de ${ }^{\circ}$ Brix final obtidos são semelhantes ao apresentado por Augustini (2007) que desenvolveu um processo de sacarificação da mandioca a partir de enzimas comerciais obtendo 9,0 para o valor máximo de ${ }^{\circ}$ Brix no hidrolisado [8].

Os valores de ${ }^{\circ}$ Brix Final (Tabela 3) foram analisados através do Software Statistic 7.0 e os resultados demonstraram que a variável concentração de crueira $\left(\mathrm{x}_{2}\right)$ e a média foram estatisticamente significativas, com p-valor $\leq 0,05$, considerando o intervalo de $95 \%$ de confiança, como evidenciado na Tabela 4.

Tabela 4. Efeito da influência das variáveis na resposta ${ }^{\circ}$ Brix.

\begin{tabular}{ccccccc}
\hline & & & & & $\begin{array}{c}\text { Estimativa } \\
\text { por } \\
\text { Fatores } \\
\text { intervalo } \\
(95 \%) \\
\text { limite } \\
\text { inferior }\end{array}$ & $\begin{array}{c}\text { Estimativa } \\
\text { por } \\
\text { intervalo } \\
(95 \%) \\
\text { limite } \\
\text { superior }\end{array}$ \\
\hline Média & $\mathbf{7 , 6 7}$ & $\mathbf{0 , 3 8 8 4}$ & $\mathbf{1 9 , 7 3 6}$ & $\mathbf{0 , 0 0 0 0 0 6}$ & $\mathbf{6 , 6 6 8}$ & $\mathbf{8 , 6 6}$ \\
$\mathrm{X}_{1}(\mathrm{~L})$ & $-0,1464$ & 0,475 & $-0,307$ & 0,7706 & $-1,3694$ & 0,538 \\
$\mathrm{X}_{1}(\mathrm{Q})$ & $-0,0416$ & 0,5662 & $-0,0735$ & 0,9441 & $-1,4973$ & 0,7065 \\
$\mathbf{X}_{2}(\mathbf{L})$ & $\mathbf{2 , 9 1 4}$ & $\mathbf{0 , 4 7 5 7}$ & $\mathbf{6 , 1 2 5}$ & $\mathbf{0 , 0 0 1 6 8}$ & $\mathbf{1 , 6 9 1 2}$ & $\mathbf{2 , 0 6 8}$ \\
$\mathrm{X}_{2}(\mathrm{Q})$ & 0,4583 & 0,5662 & 0,809 & 0,45506 & $-0,99731$ & 0,9569 \\
$\mathrm{X}_{1} \mathrm{X}_{2}$ & 0,00 & 0,6728 & 0,00 & 1,000 & $-1,7295$ & 0,8647 \\
\hline
\end{tabular}

A partir da Tabela 4 foi possível desenvolver o modelo ajustado conforme a Equação 02.

$$
{ }^{\mathrm{o}} \operatorname{Brix}=7,67+2,91 \mathrm{X}
$$

A análise de variância apresentada na Tabela 5 apresenta o valor de $F_{\text {cal }}$ para a regressão igual

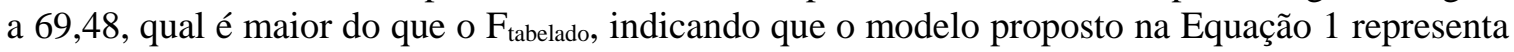


estatisticamente o processo desenvolvido. A variação explicada $\left(\mathrm{R}^{2}\right)$ de $88,47 \%$ demonstra que o modelo está adequado aos dados experimentais.

Tabela 5. Análise de variância para resposta ${ }^{\circ}$ Brix

\begin{tabular}{lcccc}
\hline $\begin{array}{l}\text { Fonte de } \\
\text { variação }\end{array}$ & $\begin{array}{c}\text { Soma dos } \\
\text { quadrados }\end{array}$ & $\begin{array}{c}\text { Graus de } \\
\text { liberdade }\end{array}$ & $\begin{array}{c}\text { Quadrado } \\
\text { Médio }\end{array}$ & F cal \\
\hline Regressão & 17,37 & 1 & 17,37 & \\
Resíduo & 2,26 & 9 & 0,25 & 69,48 \\
Total & 19,63 & 10 & 1,963 & \\
\hline \% variação explicada $\left(\mathrm{R}^{2}\right)=0,88473 ; \mathrm{F}_{1 ; 9 ; 0,05}=5,52$ &
\end{tabular}

A faixa ótima de sacarificação obtida foi de 100 a $108 \mathrm{~g} / \mathrm{L}$ de crueira e com 50 a $70 \mathrm{~mL}$ de extrato enzimático, atingindo $10{ }^{\circ}$ Brix ao final de 24 horas de hidrólise. A faixa ótima determinada pode ser identificada através da análise de superfície de resposta (Figura 1), sendo possível atingir valor máximo de $11{ }^{\circ}$ Brix. É importante destacar que com o aumento da concentração da crueira $(\mathrm{g} / \mathrm{L})$ nos ensaios, é verificado um aumento significativo da textura do material após o processo de gelatinização, dificultando a coleta das amostras para análises.

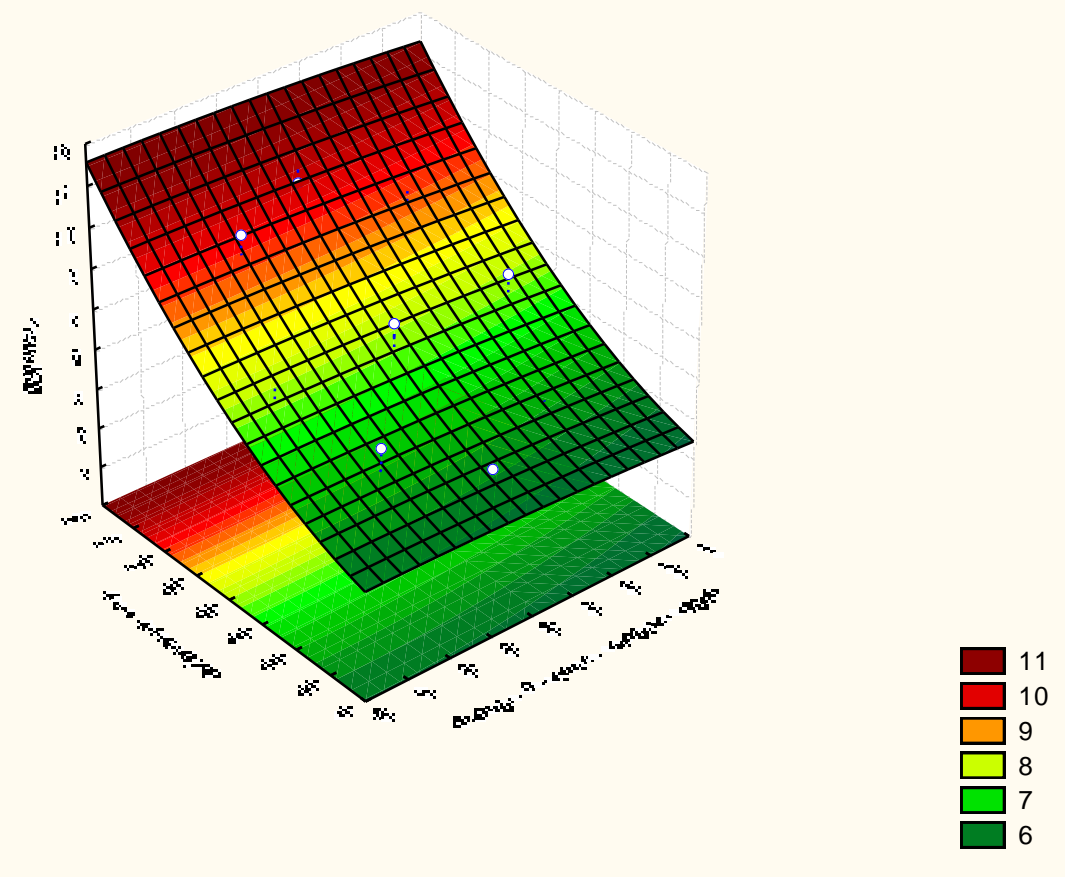

Figural. Superfície de Resposta do Planejamento Experimental Fatorial Completo $2^{2}$ para a sacarificação da crueira.

Com isso, para o desenvolvimento da cinética de sacarificação da crueira, o ensaio 03 do Planejamento Experimental foi selecionado por apresentar concentração de crueira de $100 \mathrm{~g} / \mathrm{L}$ e possibilitar o melhor manuseio para retirada de amostras quando comparado ao ensaio 08 que também apresentou o valor de $10^{\circ}$ Brix. Os resultados obtidos na cinética de sacarificação são apresentados na Figura 2. 


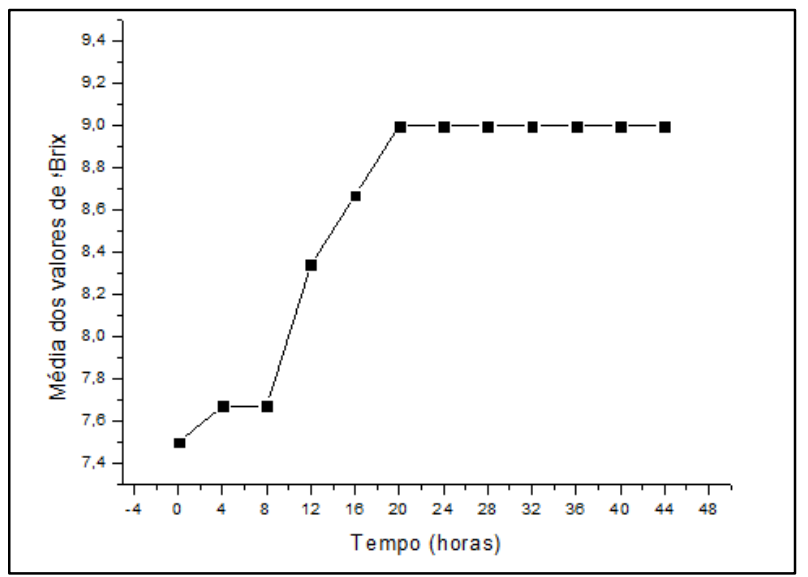

Figura 2. Resultado da cinética de sacarificação do amido da crueira

Na Figura 2 é possível verificar que a partir de 20 h de sacarificação os valores de sólidos solúveis dos ensaios atingiram o máximo, permanecendo constantes até o tempo final da sacarificação (44 horas). O desenvolvimento da cinética possibilitou a redução do tempo de sacarificação para $20 \mathrm{~h}$.

Diante do potencial da crueira para bioconversão em açúcares fermentescíveis, o presente trabalho estudou a caracterização, o processo de sacarificação enzimática através de planejamento experimental fatorial completo $2^{2}$ e a cinética de sacarificação, obtendo resultados satisfatórios e semelhantes aos dados experimentais publicados na literatura.

\section{CONCLUSÃO}

O estudo do processo de sacarificação da crueira demonstrou relevância para avaliar o potencial do resíduo agroindustrial para a produção de bioetanol. O extrato enzimático bruto produzido pelo microrganismo Bacillus sp. ANRAS02 apresentou uma atividade enzimática de 30,72 U/mL, sendo capaz de aumentar a quantidade de sólidos solúveis no meio de 1 para $10^{\circ}$ Brix. Com isso, o amido presente na farinha de crueira é transformado em açúcares fermentescíveis, podendo ser utilizado como matéria-prima potencial para a produção de biocombustíveis renováveis.

\section{AGRADECIMENTOS}

Os autores do presente trabalho agradecem a CAPES e ao CNPq pela concessão de bolsas de mestrado e iniciação científica através do Programa de Pós-Graduação em Engenharia Química (PEQ-UFS) e o projeto institucional PIBIC (PVB3842-2015).

\section{REFERÊNCIAS BIBLIOGRÁFICAS}

1. Ortiz S. Produção de bioetanol a partir de resíduos agroindustriais [dissertação]. Blumenau (SC): Universidade Regional de Blumenau; 2010. 15-25 p.

2. Santana NB. Eficiência da hidrólise de amido de mandioca por diferentes fontes de enzima e rendimento da fermentação alcoólica para produção de etanol [dissertação]. Viçosa (MG): Universidade Federal de Viçosa; 2007. 14-16 p.

3. Neves VJM.Uso do resíduo da produção de farinha de mandioca (crueira) na produção de álcool fino [dissertação]. Botucatu (SP): Universidade Estadual Paulista “Júlio de Mesquita Filho"; 2004. 55p. 
4. Collares RM. Otimização do processo de hidrólise da mandioca "In Natura" com o uso de enzima amiolíticas e pectinolíticas [dissertação]. Santa Maria (RS): Universidade Federal de Santa Maria; 2011. 21-27 p.

5. Filho WGV, Mendes BP. Fermentação alcoólica de raízes tropicais. Tecnologia, usos e potencialidades de tuberosas amiláceas Latino americanas. São Paulo: Fundação Cargill; 2003; 3(9); 530-575.

6. Xiao Z, Storms R, Tsang A. A quantitative starch-iodine method for measuring alpha-amylase and glucoamylase activities. Analytical Biochemistry. 2006 May; 351(1):146-8, doi: 10.1016/j.ab.2006.01.036.

7. Rabalho AA. Isolamento de linhagens microbianas termofílicas amilolíticas, produção, caracterização e aplicação das amilases na hidrólise do amido de mandioca [dissertação]. São José do Rio Preto (SP): Universidade Estadual Paulista; 2002. 62-63 p.

8. Augustini D, Junior HE. Produção de álcool de mandioca a partir de hidrólise enzimática natural. Synergismus scyentifica. 2007; $1-4$.

9. Carvalho RV. Produção e caracterização de $\alpha$-amilase por Bacillus sp. SMIA-2 termofílico utilizando proteínas do soro de leite, e algumas aplicações da enzima [dissertação]. Campos dos Goytacazes (RJ): Universidade Estadual do Norte Fluminense; 2007. 38 p. 